\title{
Does Globalization Affect the Performance of Secondary Education Systems? A Coevolution Model of Multiplex Transnational Networks and Educational Performance
}

\author{
Helen Seitzer and Michael Windzio
}

\section{Introduction ${ }^{1}$}

In today's globalized world, interactions between countries are manifold, where borders are fading. Globalization itself is a complex, multidimensional process. The concept of globalization refers to the historical development toward more interconnectedness between nation-states. It is also closely tied to the differential power of nation-states within a hierarchical

\footnotetext{
${ }^{1}$ This chapter is a product of the research conducted in the Collaborative Research Center "Global Dynamics of Social Policy" at the University of Bremen. The center is funded by the Deutsche Forschungsgemeinschaft (DFG, German Research Foundation)—project number 374666841 SFB 1342.
}

H. Seitzer $(\bowtie)$

Collaborative Research Centre 1342 "Global Dynamics of Social Policy", University of Bremen, Bremen, Germany

e-mail: seitzer@uni-bremen.de 
world system. Furthermore, countries exert power to influence the global distribution of economic capital (Wallerstein 1995). Countries became connected due to a multitude of reasons such as economic exchange, diffusion of culture, increasing trends in global migration, the international organization of politics, new techniques of communication, and easier access to long-distance transportation (Meyer et al. 1992; Glick Schiller et al. 1992; Castles et al. 2014; Windzio et al. 2010).

Nonetheless, asserting that the world becomes increasingly globalized and interconnected to the point where nation-states lose-or even should lose-their relevance in almost all respects is oversimplifying things. Rather than accepting this assumption, we should study the effects of globalization within various fields of society, for instance, on the performance of secondary education institutions. The rationale behind the assumption of globalization affecting societal outcomes is that more interconnectedness and exchanges between countries require similar attitudes and values, which can be expressed in similar policies and institutional structures. Similarity can be purposefully demonstrated by adopting similar institutional structures to facilitate more betweencountry exchanges. The participation in the Programme for International Student Assessment (PISA) is an example of these converging institutions. This, and the subsequent reforms in education systems, influence educational outcomes and the performance of secondary educational institutions.

Globalization can be driven by horizontal interdependencies between nation-states, for example, by global trade or migration, or it can be a result of vertical interdependencies between nation-states and international organizations (IOs) (Dobbin et al. 2007; Obinger et al. 2013; Kuhlmann et al. 2020). Empirical research should take up the challenge to investigate whether horizontal interdependencies exist and if they do, which mechanisms are driving policy diffusion in the respective field. According to the literature, the basic explanations for diffusion are (1)

M. Windzio

SOCIUM and Collaborative Research Centre 1342 "Global Dynamics of Social Policy”, University of Bremen, Bremen, Germany e-mail: mwindzio@uni-bremen.de 
learning, adoption of policies due to (2) competition, (3) imitation, or (4) coercion (Dobbin et al. 2007; Obinger et al. 2013). Correspondingly, in the case of education policy, competition for graduates and a hegemonic position in reputation due to educational quality drives the diffusion of education system characteristics, either causing countries to imitate or learn.

Since the Organization for Economic Co-operation and Development (OECD) first published their PISA in 2000 and ranked the participating countries according to their educational performance, existing research has revealed considerable influence of these rankings on domestic education policymaking (Niemann 2014; Martens et al. 2014). By publishing these benchmarks, the OECD stimulated the above-mentioned competition among those countries that considered education an important condition for their economic and social development. In the literature, this has been described as vertical interdependence between IOs and countries participating in or observing the PISA studies. Being interconnected within global networks in a competitive situation provides many opportunities to learn from or to imitate better-performing countries. Diffusion by learning or imitation can be a way of coping with the intensified competition. The increased performance in secondary education is ultimately an outcome of this diffusion process.

In this study, we take a macro-quantitative approach to diffusion through vertical and horizontal interdependencies. We focus on domestic secondary education systems and investigate whether three subdimensions of globalization affect their performance: the global exchange of tertiary students, global migration, and global service sector trade. We utilize relational and time-varying measures of these globalization indicators. More precisely, these indicators are dynamic networks in which the set of countries remains constant, but the ties among them change over time. By analyzing the coevolution of these networks and countries' performance in the PISA study, we can simultaneously test the impact of globalization on domestic secondary education systems and investigate the impact of performance in the PISA study on global exchange patterns. Our assumption is, therefore, that countries that are highly interconnected due to these networks are just that due to their educational outcomes. We expect, for example, that a difference in performance might 
influence service sector trade toward higher-scoring countries, which then stimulates lower-scoring countries to reinvent their education system to compete in the game of hegemonic education.

The exchange of persons, whether short term for educational purposes in terms of student mobility or permanently in the form of migration flows, ties countries together but often presupposes institutionalized conditions that allow this exchange to occur in the first place. In the interconnected web of entities, a country's reputation or prestige (Alderson and Beckfield 2004) is one factor determining institutionalized exchanges. However, it is not countries as abstract entities that form reputations among one another but rather everyday people who hold judgments on and prejudices against countries, thus helping to establish their reputation (Beghin and Park 2019). The question here is whether longestablished and stable interrelations, such as migration or trade flows, are being redirected by recent changes in countries' reputations. PISA significantly influences the perception of a country's educational quality through the triennial rankings of student achievement, but this influence does not necessarily surpass the prejudice of local customs (Waldow et al. 2014). This new threat to national legitimacy and reputation raises the question of whether similarities and differences in PISA scores and rankings influence student exchange, migration patterns, and service sector trade flows. Are persons looking to migrate aware of a country's reputation due to PISA rankings and, therefore, follow this pattern, or are these exchange flows uniquely dependent on institutionalized pathways, which are not threatened by changes in an international reputation? Moreover, do countries adapt to the performance of countries that they are tied to in the global network?

\section{Theory}

International relations at the country level are influenced by a multitude of national factors, including but not limited to shared goals and standards (e.g. the establishment of the Sustainable Development Goals or human rights). According to Wallerstein's World Systems Theory, education adapts to accommodate the spread of capitalism (Wallerstein 1995). 
However, this focus is heavily dependent on an economic perspective, dismissing all other influences on the diffusion of education policy. Groundbreaking in this theory, however, is the growing interdependence of nation-states. From this perspective, international migration and increased student exchanges may be a result and function of the spread of capitalism. The core-periphery structure of the world described in Wallerstein's theory suggests that people from the 'periphery' are drawn to the 'core' of the world system, regardless of national borders. Similarly, capital, but also educational hegemony is distributed unequally throughout the system with core-countries possessing not only the lion's share in an economic sense but also the power to influence, accept, or reject policy suggestions from other parties such as IOs. In turn, aspects of education systems are diffused to the periphery from the core. An extreme case of this demonstration of educational hegemony lies in the diffusion of the language of instruction from the colonizers to the colonies (Griffiths and Arnove 2015). Given the fact that PISA was not only developed in a rather central country (France) but was also initially developed for central European countries, taken together with the criticism of PISA's Eurocentrism and cultural bias (Zhao 2020), it could be assumed that these central countries would perform significantly better in the test than more peripheral countries. Central countries in the network of student exchange and migration would rank higher in PISA, while peripheral countries catch up over time. Service sector trade might have the opposite effect, as countries with lower scores most likely take on more 'outsourced' labor from countries with a higher rank in PISA. Wallerstein suggests that these networks tend to converge to a maximum before the network evolution comes to a halt. This theory, however, does not account for the potential influence of PISA scores on the network patterns; instead, it may suggest no influence at all.

Another theory on the homogenization of the world originated in the 'Stanford school' of global isomorphism. John Meyer and colleagues' World Society Theory (Meyer et al. 1997) accounts for the homogenization of education systems and the international alignment of goals, such as PISA participation, along with the joint acceptance of a model of democracy and human rights. This theory highlights the importance of legitimacy due to the acceptance of world polity standards. The theory 
does not explicitly predict an increase in global interaction as Wallerstein's theory suggests. It does, however, account for the creation and spread of 'myths' of countries' reputations, thus allowing the potential to create a reputation that contributes to the pull factors of migration and student exchange. This is where PISA rankings unfold their influence: The rankings inform the 'myth' of a country, influencing the popular perception of the quality of public (welfare) policy through implementing the notion of a good education system. This in turn fosters international relations and potentially increases migration flow.

Wallerstein includes a stronger account of the core-periphery structure of migration patterns through the emphasis on commodification, which Meyer and Ramirez's theory does not. PISA rankings are often associated with development, which would indicate a correlation of PISA scores and a more central network position, meaning a greater influx of people, which is in line with Wallerstein's approach. Meyer's theory would suggest a similar association but would predict an increase in migration inflow due to the changing popularity of a country. However, we will not be able to disentangle the differentiation between both mechanisms in this study. Instead, what we can test is whether there is indeed an increasing influx of people, coevolving with the change in PISA scores.

Both theories could shed some light on migration patterns as well as student mobility. They suggest that participation in PISA may influence international relations, with Wallerstein's theory emphasizing the economic aspects, whereas Meyer and colleagues' theory indicates a more culturally driven approach. While the former suggests a correlation between rankings and network centrality, the latter indicates a causal effect. But, as stated before, PISA results do not only influence national policymakers but also increase the competition and interaction between countries when it comes to the quality of education systems (Bieber and Martens 2011). As shown in existing research, cross-national comparisons, policy transfer, and exchanges between countries have been rapidly increasing in the wake of the PISA study (Steiner-Khamsi 2014). The public discussion of PISA scores and the naming and shaming of countries' outcomes greatly influence countries' reputations with other countries and their own citizens. While PISA rankings, as published by the OECD, may influence a countries' reputation, the cleaned PISA scores 
might not necessarily confirm this effect. PISA scores are, in contrast to the rankings, displaying the countries educational effectiveness given its social circumstances, for example, the number of people with an immigrant background, the number of girls tested, the qualifications of teachers, and so on. This can result in different outcomes. In support of Meyer's theory, we expect an effect from the rankings, as they are publicly discussed. The scores relate more to Wallerstein's classification of core and peripheral countries, as the educational hegemony often goes along with this classification.

Reputations and prejudices inform interactions between citizens on an individual level but also determine larger trade volumes, as the demand for products from a certain country can diminish with its declining reputation or be reinforced due to a positive appraisal, thus leading to the strengthening of political interdependencies or disagreements ( $\mathrm{MaOz}$ 2011). Adhering to similar standards in welfare politics is a prominent determinant of political interdependencies and policy diffusion (Robertson and Dale 2015). The participation in and results of International Large-Scale Assessments (ILSAs) like PISA might be a new way to foster international relations, as not only the participation but also the implementation of reforms as a reaction to results are seen as legitimizing instruments (Addey et al. 2017). Regarding legitimization within a given country, a way to cope with the intensified competition can be to gather information on the education systems of better-performing countries. The diffusion mechanisms of learning and imitation can thus help cope with this challenge, which requires contact with other countries based on an underlying social network.

Global trade and its increase over recent decades, combined with the increasing importance of the service sector economy, are important aspects of globalization (Glick Schiller et al. 1992). In contrast to the exchange of raw material, service sector trade relies more on communication and social interaction. Particularly in highly qualified and specialized economies, such as information technology or the knowledge economy, trade partners mutually rely on the trade partners' educational standards.

Moreover, countries become more attractive as destinations for global student mobility if they are closely linked to the home country by service sector trade, as students' employment prospects might increase if they are 
familiar with modes of communication and knowledge production in both countries. For this reason, we expect that global student mobility corresponds with the educational standards in the sending and receiving countries but also with the service sector trade flows between these two countries.

International migration is driven by various factors (Windzio 2018; Windzio et al. 2019). These factors can be categorized as economic, ecologic, demographic, and political. Much like trade flows, migration flows also follow the famous gravity model (Walsh 2011): Geographical proximity, cultural and linguistic similarities, as well as historical interlinkages determine the destinations of goods and people alike. Student exchange follows similar patterns to migration and could even be seen as a form of 'short-term migration' or 'trial migration' since some graduates of higher education remain in their destination country (Vögtle and Windzio 2020).

Since the sending and receiving countries' characteristics influence migration and student exchange patterns, we wonder whether PISA results belong to the list of push or pull factors for international interdependencies. While PISA strongly influences policymaking, does it also inform the public to a level where rankings determine a country's international reputation? Does PISA influence the policymaking process to the extent that it affects international relations, and how much of that influence trickles down to the population? Do citizens consider PISA as an instrument to determine which country has a suitable education system and might be a worthy destination country? Does the embeddedness of a country in global networks influence the performance of its secondary education, for example, due to 'social remittances', learning or imitation? We will address these questions by simultaneously inspecting three networks, specifically student exchange, migration, and global service trade; we then combine them with changing PISA rankings for Mathematics in a network coevolution model. 


\section{Previous Research}

As this chapter includes four variables of interest, the change in student exchange patterns, the development of migration stock, global service sector trade, and PISA rankings and scores, this section discusses multiple aspects of previous research.

When choosing a destination country for degree-seeking student exchange, students take a multitude of factors into account (Vögtle and Windzio 2016). Most studies involving a network perspective utilize a macro-level perspective. Studies show that the student exchange network has undergone considerable changes and developed an increasingly unequal and centralized topology. This observation hints toward an academic hegemony that is consistent with economic performance (Barnett and Wu 1995; Shields 2013). Moreover, student exchange patterns follow economic development and exchange (Barnett and Wu 1995; Shields 2013; Vögtle and Windzio 2016). In addition, it is a common approach to consider the geographical proximity, shared borders, shared colonial history, and similar cultural aspects such as language similarity and religious factors as determinants of student mobility (Vögtle and Windzio 2016; Barnett et al. 2016).

Some students study abroad with the prospect of staying in their destination country (Peterson et al. 1984), and these 'tentative migrants' link the network of student mobility to the network of global migration. These graduates are particularly attractive in economic segments, where they can rely on their familiarity with both countries, their country of origin, and the country of destination. This argument might be particularly important for service sector industries where young graduates often begin their occupational careers. In general, reasons for migrating to different countries are similar to reasons why young students seek certificates in other countries: Economic, cultural, and social motivations are among the top pull factors for migration (Windzio 2018). Migration for the benefit of future children's lives and education are potential reasons for migration, especially for families or younger generations. In addition, according to gravity theory (Boyle et al. 1998), geographic proximity and contiguity play a major role in migration patterns. Moreover, a 
core-periphery topology (Windzio et al. 2019) as well as a South-toNorth migration movement can be observed (Jennissen 2007).

In contrast to global student mobility, however, the general global migration stock results from various forms of migration, for example, labor migration, refugees, family reunification, and student mobility. Although the migration of refugees is mostly directed toward economically well-performing countries, less developed countries also host many refugees, such as Turkey, Colombia, Pakistan, and Uganda (https://www. unhcr.org/refugee-statistics/). Moreover, global migration may increase opportunities to become involved in global trade since migrants' economic transnational activities link sending and receiving countries together (Glick Schiller et al. 1992).

The flow of so-called social remittances (Lacroix et al. 2016) could be one reason why, in the long run, sending and receiving countries assimilate to each other with respect to the performance of their education systems. Much like student mobility and global trade, these migration networks provide information channels and, thereby, the conditions for learning from and imitating other countries. The question is whether the isomorphism of education systems is influenced by the rising numbers of migrants, as similar education systems allow for easier integration of migrant children into schools.

Educational performance might be crucial for service sector trade. Some foreign students stay as 'tentative migrants' after graduation in order to work in highly qualified jobs, often in the service sector or trade related to the country of origin. Strong ties in service sector trade might correspond with migration and student mobility but also with performance of the education system. In contrast to industrial production, service sector trade relates to what people $d o$ to customers, so that a similar level of qualification and communicative capacity is required. If the average level of educational performance strongly differs between two countries, this asymmetry might affect the myriads of single economic transactions in the service sector industry, so that countries interacting either have similar average levels of educational performance or try to increase their educational performance or assimilate to their partners' performance levels. 
The influence of PISA on international relations is somewhat ambiguous. As stated before, the initial argument as to why participation in the PISA study might have an effect on international relations points to legitimacy. According to World Society Theory, participating in PISA demonstrates a country's willingness to follow norms of the world society (Addey et al. 2017). In addition, participation facilitates the acquisition of development aid funds (Kijima 2010). However, to date, there has been no clear empirical evidence of exactly how participation in PISA might influence international relations. One assumption is that migration and student exchange patterns follow changes in PISA scores and rankings, as people looking to travel or to migrate choose countries with a good international reputation. To determine whether the PISA scores and rankings do influence peoples' decision-making regarding migration and exchange destinations, we ask if these patterns of international exchange coincide with PISA scores and rankings. In our model, we include network effects of degree-seeking student exchange flow, migration stock, and service sector trade flow. We also include independent variables representing the classic approach to migration and student exchange patterns: gross domestic product (GDP) per capita, cultural aspects such as language and religious similarity, contiguity, and the ratification of free trade agreements. In addition, we include the number of top-ranking universities in a university ranking to represent the popular perception of the quality of the higher education system.

\section{Data}

All data for the following analysis was collected every three years from 2006 to 2018, resulting in 5 data points. Missing observations in the migration stock data were interpolated linearly. A total of 49 countries and subregions were included in the sample due to their consistent participation in PISA. ${ }^{2}$

\footnotetext{
${ }^{2}$ Australia, Austria, Belgium, Bulgaria, Brazil, Canada, Switzerland, Chile, Colombia, Czech Republic, Germany, Denmark, Spain, Estonia, Finland, France, United Kingdom, Greece, Hong Kong, Croatia, Hungary, Indonesia, Ireland, Iceland, Israel, Italy, Jordan, Japan, South Korea, Lithuania, Luxembourg, Latvia, Macao, Mexico, Netherlands, Norway, New Zealand, Poland,
} 
In the coevolution model of networks and a related outcome measure (see below), outcomes of influence are often called the 'behavior'. We collected data on our outcome of interest, PISA scores, and rankings, from the original information published by the OECD. To obtain measures most likely to influence the public's perception of a country's quality of education, the OECD published rankings in Mathematics that were derived from the original data. ${ }^{3}$ We did not adjust these rankings for domestic factors since we were not interested in replicating the OECD's rankings. For reasons of simplicity and due to requirements of the models presented below, we separated the distribution into 10 percentiles. Additionally, we computed PISA country scores, as opposed to rankings, by using a hierarchical linear regression model with individual and country levels from the original OECD data (Teltemann and Windzio 2019). The final scores included in this analysis are country-level random effects, indicating the deviation of each country's mean PISA scores from the overall mean in the respective year while controlling for individual, school, and aggregated country characteristics. The conditional country scores were adjusted for gender, immigrant background (native, first, or second generation), the number of books at home, if the language spoken at home was the test language, cultural resources and possessions at home, ESCS (Economic, Social, and Cultural Status), and parental education level, as well as the percentage of girls per school, the percentage of certified teachers, ability grouping, school size, and student-teacher ratio. The missing values for the immigrant background for Japan in 2018 were recreated with available information (country of birth of parents and self). The analysis was weighted with standardized senate weights, so every country contributed equally to the analysis, irrespective of the year since the country size is not relevant in this case. All five plausible values were used. School-level variables were aggregated to percentages at the country level to treat missing data. Just like the rankings, the scores were split into 10 percentiles.

Portugal, Qatar, Romania, Russian Federation, Slovakia, Slovenia, Sweden, Thailand, Turkey, Uruguay, USA

${ }^{3}$ http://www.oecd.org/pisa/data/. 
The service trade networks for the respective years were obtained from the United Nations Conference on Trade and Development (UNCTADstat Trade in Goods and Services 2020). The original data provided general trade flows as continuous information rather than discrete categories. Since the values for Switzerland and Liechtenstein are combined, but Liechtenstein does not have individual trade values nor is it part of our sample, the values were adopted for Switzerland. Trade ties are normalized on the amount of total export of each country, describing the importance of each receiver (alter) to the respective sender (ego) measured by the percentage of ego's total trade going to that specific alter. We then only included ties if the respective trade volume was above $80 \%$ of the overall trade volume. Figure 4.1 shows the trade network in 2012.

The student mobility data was collected from the UNESCO Institute of Statistics (UIS) (UIS 2020). The data contains the numbers of inbound degree-seeking students by country of origin and was normalized on the origin countries' enrolment numbers in tertiary education (UIS and own

\section{Service Sector Trade Flow in 2012 Export normalized on Total Export}

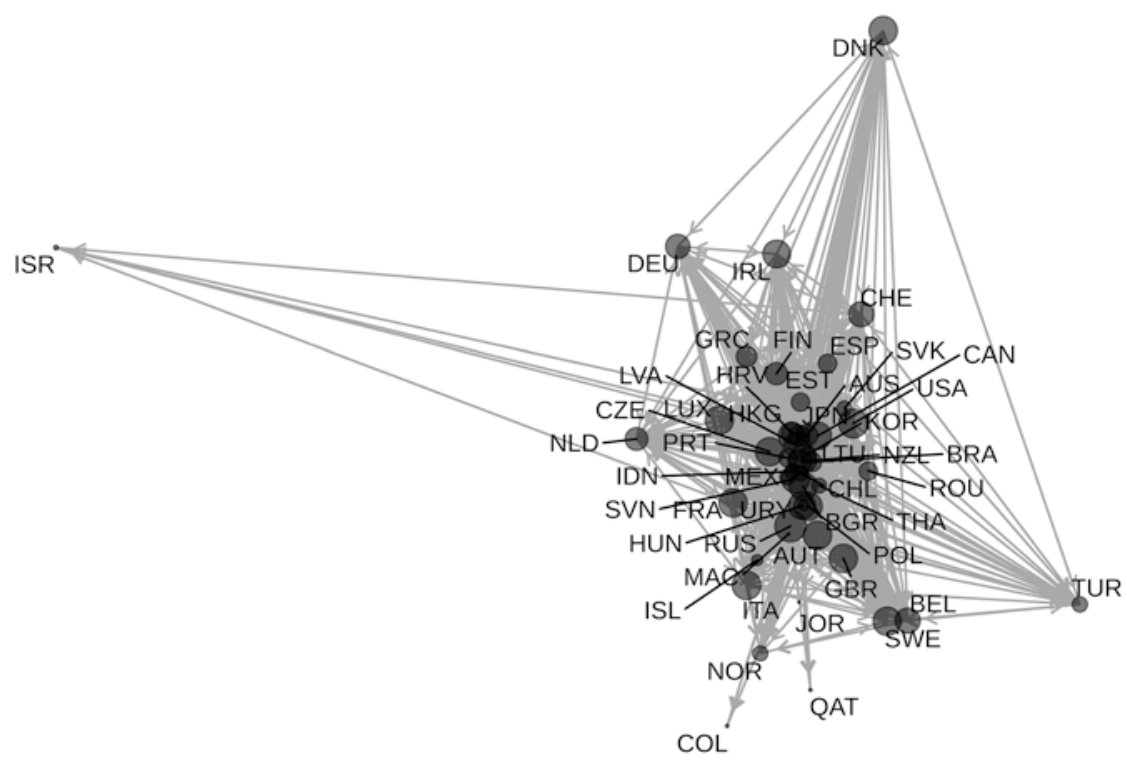

Fig. 4.1 Service sector trade flow in 2012. Export normalized on total export 
collection). Accordingly, the exchange students then represent the percentage of enrolled students from ego studying in specific alteri. Much like service trade, only the top $20 \%$ of all student flows were coded as ties between countries. Figure 4.2 shows the student exchange flow in 2018.

We obtained the migration stock data from the United Nations Database ( 2019) and calculated the migrants as the percentage of the sending country's population (Windzio 2018; World Bank 2020) living in a receiving country. Similar to the other networks, a tie was only coded if the percentage of migrants surpassed $80 \%$ of the total migration flow. Figure 4.3 shows the migration flow network in 2015.

All three networks are increasing in density, where the density of the student exchange network rises from 0.163 to 0.251 , the Migration network from 0.180 to 0.218 , and the service sector trade network from 0.142 to 0.234 , with an average degree of 9.469, 9.576, and 9.624,

\section{Student Exchange Flow in 2018 by Percentage of Enrolled Tertiary Students}

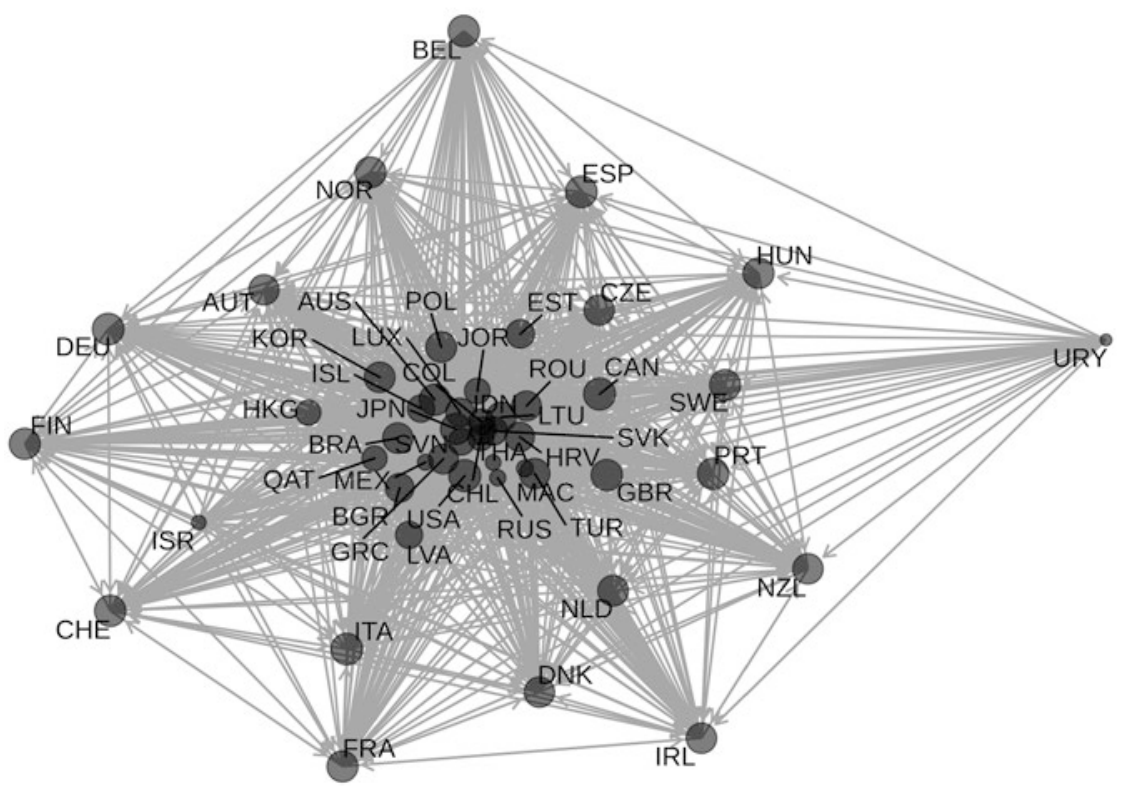

Fig. 4.2 Percentage of exchange students in 2018 depending on the number of enrolled students 
Migration Stock in 2015 Normalized on the Percentage of Population Abroad

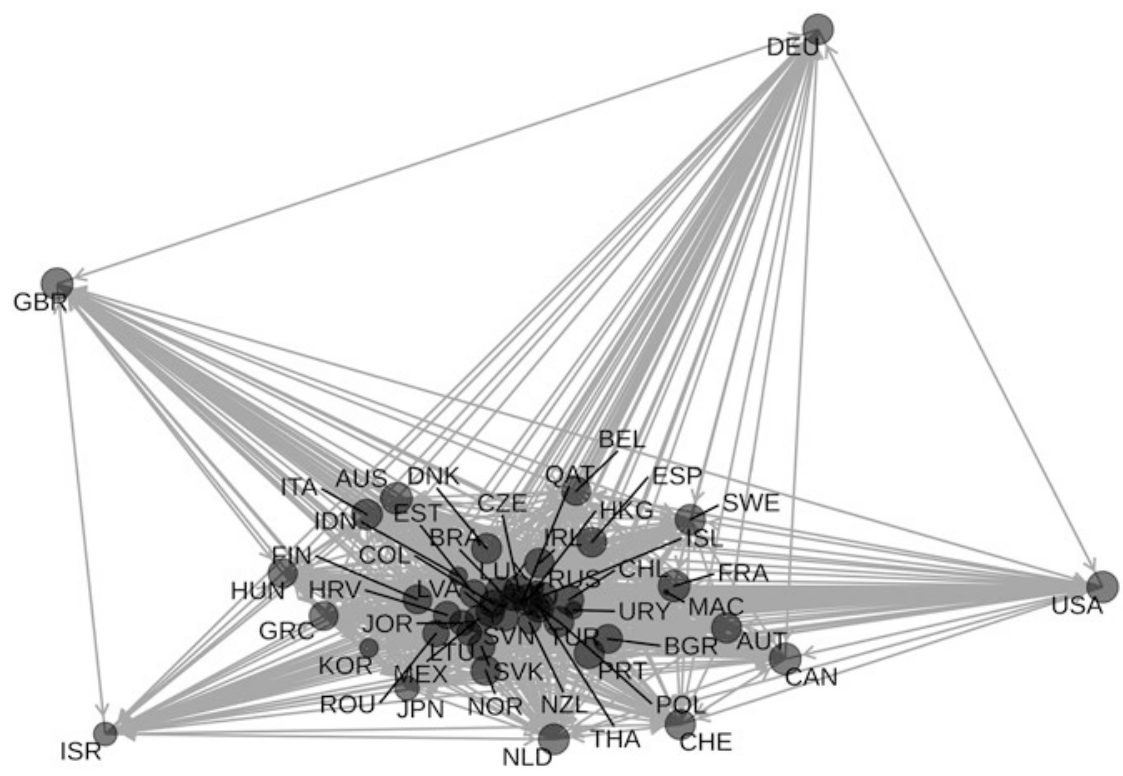

Fig. 4.3 Migration stock in 2015 as a percentage of ego's population living in the respective alter country

respectively. Despite the rising density, they are relatively stable, as the student exchange network has Jaccard indexes between the waves around 0.7 , the migration network around 0.9 , and the trade network has increasing values between 0.6 and 0.9 . These values in combination with the increasing density show that the networks are relatively stable and rarely devolving. New ties are being built and existing ties maintained, but the number of breaking ties is extremely low.

Further data included was collected from the Centre d'Études Prospectives et d'Informations Internationales (CEPII) to account for variances usually captured by a gravity model approach. Specifically, we accounted for language similarity (lp2) (Melitz and Toubal 2012), common religion, the ratification of free trade agreements (FTA-WTO) (Head and Mayer 2014), contiguity (shared borders or water), and former colonial ties (Mayer and Zignago 2011). The GDP per capita in 
constant 2010 US Dollars was collected from the World Bank (World Bank 2019). Furthermore, a proxy for the quality of higher education was developed from the Shanghai Rankings, ${ }^{4}$ counting the number of universities in the top 100 rankings each year. Regardless of the practices that construct these rankings, the average student might still consider it an important source in their decision process regarding the choice of the destination country.

\section{Methods}

Recent developments in longitudinal social network analysis culminated in stochastic actor-based models (SAOMs) of network evolution (Snijders et al. 2010). The underlying rationale is that cross-sectional network analysis assumes that actors are in a Nash-equilibrium regarding the costs and benefits of their ties so that none of these actors has an incentive to change their social relations by either establishing a new tie or dropping an existing tie. Relaxing this unrealistic assumption requires a longitudinal perspective on network evolution. A social network is a higher-level structural outcome of actors' individual decisions on whom they would prefer to be linked to in this network. Actors' basic motive behind their network decisions is maximizing their utility. If the utility of closing triads or reciprocating an incoming tie is comparatively high, the model assumes that actors prefer these decisions to existing alternatives, for example, to establishing a tie that does not close an open triad. The question in the actor-based network model is: What does it take for an actor to establish, maintain, or dissolve a tie? SAOMs specifically assume that actors change or maintain their ties depending on the cost of this action, instead of assuming a relative 'laziness' of networks. Ties are easier to maintain and establish if the actors have either attributes in common or both benefit from the attribute imbalance. This perspective requires longitudinal data, especially if actor attributes change over time, as the attributes' changes might coincide or even induce changes in the network. In the specific case of a coevolution model, not only is the network

\footnotetext{
${ }^{4}$ http://www.shanghairanking.com/ARWU-Statistics-2018.html.
} 
dependent on the previous waves' network composition, but also on the levels of a 'behavior', an additional dependent variable that in turn also changes due to the networks' composition.

The application of this model utilizes simulation algorithms based on multinomial discrete choice models (Greene and Hensher 2010) of tie creation, tie dissolution, or inactivity. Hence, it derives the utility of a local (actor-based) network characteristic from their empirical distribution in the network. Examples of such characteristics are reciprocity, transitive triads, or homophily with respect to actor attributes. The algorithm simulates the transition from the network at $t$ to $t+1$ by simulating utilitymaximizing decisions at the actor level and thereby finds those logit coefficients for the specified regression model that make this transition most likely. Based on these so-called micro-steps, the regression equation predicts networks for the subsequent periods. If the explanatory variables specified by the researcher do not sufficiently explain this transition, the simulated networks will not fit well to the empirical network in the subsequent period.

In addition to overcoming the restrictive equilibrium assumption in most cross-sectional network analyses, the SAOM's longitudinal approach allows for the disentanglement of ego's selection process into a particular network tie, for example, by homophily, from the influence of nodes the ego is connected to (Steglich et al. 2010). This feature of the SAOM is important for our analysis since we are also interested in how countries' characteristics - in our case their performance in the PISA study — change according to the influence of the countries they are tied to in the respective network. To do so, however, we have to control for the selection processes into these networks: Countries either establish network ties due to their similarity in educational performance (which we will call "PISA" in the following), or they assimilate to the educational performance of their alteri, or they do both. The coevolution model for selection and influence provides a multi-equation system that can separate these processes. 


\section{Results}

In the following, we analyze the coevolution of three networks—student exchange, migration stock, and service trade — and secondary education performance as indicated by PISA scores. In addition, the unadjusted PISA rankings as published by the OECD were included as 'behavior', more precisely, as the countries' characteristic that could be under the influence of the alteri in the network. A set of additional predictors was included which can be categorized as follows: economic (GDP per capita in 10,000), geographic (contiguity: shared borders), cultural (language similarity, common religion), and educational (interactions with the 'behavior', number of top-ranking universities in the top 100 Shanghai Ranking). Thus, the main interest lies in detecting (a) how the networks influence each other; (b) if the PISA rankings have an effect on the change in network structure, as well as on the networks correlating with the PISA rankings; (c) whether other countries that a focal country (ego) is tied to influence ego's education system; and (d) whether network partners influence each other in the PISA ranking and score.

Table 4.1 shows the results of four equations representing the effects on our three networks and on the outcome of educational performance. The first three equations show determinants of selection into network ties, whereas the fourth equation (Behavior) shows the effects on social influence exerted by alteri that ego is tied to. Each network equation includes structural effects. The term "density" is a regression constant, showing the density of the network if all explanatory variables are set to zero. Moreover, reciprocity accounts for the propensity to reciprocate an incoming tie, whereas the GWESP (geometrically weighted edgewise shared partners) term accounts for transitivity (Harris 2014).

The goodness of fit statistics (not shown) demonstrate a sufficiently good fit for behavior and outdegree distribution. Nonetheless, there are significant deviations from the empirical indegree distribution in all three networks, although the overall fit is acceptable. We focus our interpretation on Model 2 (M2) in Table 4.1, where we calculated educational performance as adjusted PISA scores as opposed to PISA rankings. 
Table 4.1 The coevolution of networks of global trade, migration, student mobility, and PISA performance

\begin{tabular}{|c|c|c|c|c|c|c|}
\hline \multirow[b]{2}{*}{ Network effects } & \multicolumn{3}{|c|}{ M1: Rankings } & \multicolumn{3}{|c|}{ M2: Scores } \\
\hline & EST & SE & & EST & SE & \\
\hline \multicolumn{7}{|l|}{ Student exchange network } \\
\hline Density & -1.273 & 0.131 & $* * *$ & -1.28 & 0.128 & $* * *$ \\
\hline Reciprocity & 0.77 & 0.111 & $* * *$ & 0.772 & 0.108 & *** \\
\hline GWESP & -0.025 & 0.097 & & -0.017 & 0.097 & \\
\hline Language similarity & -0.038 & 0.046 & & -0.031 & 0.045 & \\
\hline Common religion & -0.086 & 0.175 & & -0.057 & 0.174 & \\
\hline Contiguity & 0.392 & 0.187 & * & 0.43 & 0.194 & * \\
\hline PISA alter & 0.009 & 0.018 & & 0.021 & 0.056 & \\
\hline PISA ego & - & - & & -0.106 & 0.054 & * \\
\hline PISA similarity & 0.202 & 0.175 & & 0.032 & 0.309 & \\
\hline GDP alter & -0.03 & 0.022 & & -0.027 & 0.02 & \\
\hline No. of top 100 univ. alter & -0.023 & 0.007 & $* * *$ & -0.023 & 0.007 & $* * *$ \\
\hline Crprod migration & 0.419 & 0.098 & $* * *$ & 0.413 & 0.104 & $* * *$ \\
\hline Crprod reciprocity with migration & 0.223 & 0.108 & * & 0.211 & 0.112 & + \\
\hline Crprod trade & 1.433 & 0.11 & $* * *$ & 1.435 & 0.113 & $* * *$ \\
\hline Crprod reciprocity with trade & 0.194 & 0.135 & & 0.202 & 0.131 & \\
\hline \multicolumn{7}{|l|}{ Migration stock network } \\
\hline Density & -0.56 & 0.321 & + & -0.52 & 0.369 & \\
\hline Reciprocity & 0.923 & 0.257 & $* * *$ & 0.922 & 0.264 & $* * *$ \\
\hline GWESP & 0.193 & 0.223 & & 0.202 & 0.244 & \\
\hline Language similarity & 0.183 & 0.107 & + & 0.191 & 0.108 & + \\
\hline Common religion & -0.5 & 0.464 & & -0.499 & 0.456 & \\
\hline Contiguity & -0.735 & 0.554 & & -0.812 & 0.564 & \\
\hline PISA alter & -0.045 & 0.041 & & 0.07 & 0.119 & \\
\hline PISA ego & - & - & & 0.241 & 0.268 & \\
\hline PISA similarity & -0.134 & 0.411 & & -0.699 & 0.87 & \\
\hline GDP alter & -0.113 & 0.057 & * & -0.159 & 0.055 & $* *$ \\
\hline Crprod stud & 0.534 & 0.321 & + & 0.525 & 0.327 & \\
\hline Crprod reciprocity with stud & 0.095 & 0.352 & & 0.106 & 0.342 & \\
\hline Crprod trade & 0.7 & 0.312 & * & 0.675 & 0.314 & * \\
\hline Crprod reciprocity with trade & -0.148 & 0.331 & & -0.154 & 0.35 & \\
\hline \multicolumn{7}{|l|}{ Service sector trade network } \\
\hline Density & -1.11 & 0.143 & $* * *$ & -1.113 & 0.147 & *** \\
\hline Reciprocity & 0.948 & 0.133 & $* * *$ & 0.943 & 0.122 & *** \\
\hline GWESP & -0.196 & 0.106 & + & -0.187 & 0.112 & + \\
\hline Contiguity & -0.236 & 0.249 & & -0.246 & 0.255 & \\
\hline Colony & -0.32 & 0.277 & & -0.334 & 0.286 & \\
\hline FTA-WTO reciprocity & 0.227 & 0.191 & & 0.198 & 0.191 & \\
\hline PISA alter & 0.049 & 0.019 & * & 0.113 & 0.057 & * \\
\hline
\end{tabular}


Table 4.1 (continued)

\begin{tabular}{llllllll}
\hline & \multicolumn{2}{l}{ M1: Rankings } & \multicolumn{3}{l}{ M2: Scores } \\
\hline Network effects & EST & SE & & EST & SE & \\
\hline PISA ego & - & - & & 0.068 & 0.065 & \\
PISA similarity & -0.126 & 0.19 & & -0.586 & 0.336 & + \\
GDP alter & -0.059 & 0.025 & $*$ & -0.045 & 0.022 & $*$ \\
Crprod stud & 1.636 & 0.129 & $* * *$ & 1.649 & 0.132 & $* * *$ \\
Crprod reciprocity with stud & 0.324 & 0.149 & $*$ & 0.32 & 0.151 & $*$ \\
Crprod migration & 1.04 & 0.113 & $* * *$ & 1.003 & 0.113 & $* * *$ \\
Crprod reciprocity with migration & -0.359 & 0.129 & $* *$ & -0.344 & 0.122 & $* *$ \\
Behavior: Educational & & & & & & \\
performance & & & & & & \\
PISA linear shape & -0.091 & 0.141 & & 0.008 & 0.162 & \\
PISA quadratic shape & -0.127 & 0.155 & & -0.829 & 0.503 & + \\
PISA average sim. (stud) & 1.669 & 7.607 & & 4.418 & 8.293 & \\
PISA average sim. (migr.) & -12.264 & 12.313 & & -5.528 & 9.758 & \\
PISA average sim. (trade) & -0.789 & 7.274 & & -4.627 & 8.589 & \\
Effect from GDP & 0.03 & 0.049 & & 0.174 & 0.074 & $*$ \\
All convergence t ratios & $<0.07$ & & & $<0.09$. & & \\
Overall max. Convergence ratio & 0.21 & & & 0.29 & & \\
\hline
\end{tabular}

$N=49$ countries, 2006, 2009, 2012, 2015, 2018

Note: $+p<0.1 ; * p<0.05 ; * * p<0.01 ; * * * p<0.001$

Source: WeSIS data base, own computation

In M2 from Table 4.1, we can see that the student exchange network depends not only on reciprocity but also on spatial proximity, measured here as contiguity. If two countries share a border, the log odds of observing a tie in the student mobility network increase by $0.43^{*}$. We find a significantly negative effect of ego's scores on ties in the student exchange network, which probably indicates that students in high-performing countries prefer to study in their home country. In contrast to our expectation, there is a negative effect of the number of high-ranking universities. This is a rather surprising result, as one would expect more students to aspire to go to countries hosting these universities. This result raises the question whether countries with many high-performing universities are open to students from all over the world or whether the incoming student population in these countries is highly selective and limited to just a few sending countries. Yet, due to a higher influx of foreign students, these universities might impose a more challenging selection process for admission and thereby restrict the inflow. The debate on restrictions 
imposed on the admission of high-performing Asian applicants by Harvard University points in this direction: "Asians are demographically overrepresented minorities, but they are underrepresented relative to the applicant pool" (Gersen 2017).

Moreover, we find a significantly positive effect of the migration stock network on the student exchange network $\left(0.413^{* * *}\right)$ : Students prefer to go to countries where their origin country has already established ties in the global migration network. In addition, there is an effect of reciprocated ties in the migration network on the student exchange network, but it is significant only at the $10 \%$ level $(0.211+)$. Furthermore, the student exchange network depends on the service sector trade network since there is a positive effect of this network on student exchange $\left(1.435^{* * *}\right)$. Aside from that, we cannot observe any significant determinants of ties in this network. There are neither ego nor alter effects of the PISA scores, nor do we find homophily with respect to the PISA scores: The effect of selection into these networks due to PISA similarity is not significant.

In the next equation, the global migration stock network is the outcome of interest. This network leans toward reciprocity and shows a (marginally significant) positive effect of language similarity. It also displays a negative effect of alter's GDP, which is a rather unexpected result. This might originate from the limitation of our dataset, namely, that it is based on 49 economically developed countries that participated in the PISA study. However, there is a significantly positive effect of service sector trade. Patterns of global migration do follow linkages in the increasingly globalized network of service sector trade.

Likewise, the trade network tends to produce reciprocating ties, but here we see a positive effect of 'PISA alter', which means that service sector trade ties are directed toward countries with higher PISA scores (and rankings in M1) $\left(0.113^{*}\right)$. A striking result, however, is the negative coefficient of 'GDP alter', indicating that the better another country performs economically, the lower the propensity for ego to establish a tie in the trade network. Yet, we should keep in mind that this effect is conditional on the interdependency among our three networks: Here we find robust significant effects of student mobility ties on service sector ties $\left(1.649^{* * *}\right)$ as well as on ties in the migration stock network $\left(0.113^{* * *}\right)$. While there is an additional effect of reciprocated ties in the student 
network $(0.32 *)$, reciprocity in the migration network tends to reduce the main effect of nonreciprocated ties in the migration network $\left(-0.344^{* *}\right)$. Consequently, these three networks are highly interrelated. The positive effect of service trade indicates that student exchange, albeit partly dependent on the choice of the traveling individual, might follow already institutionalized patterns of exchange. Accordingly, migration follows the service trade patterns as well, although with a noticeably smaller effect. The opposite is also true, with student exchanges and migration patterns strongly influencing the service trade flow as well.

We regard educational performance as the outcome in the last equation (Behavior). "Linear shape" and "quadratic shape" are important to control for simultaneous growth processes in the overall population. However, according to our results, neither PISA rankings nor PISA scores are influenced by the alteri in the network. For each network, we estimated the effect of average similarity. A positive effect would indicate that ego becomes similar to the average PISA ranking or score of those countries that ego is connected with. We conclude from these results that national systems of secondary education might be exposed to top-down influence exerted by international organizations. Even though countries might adapt their own policies due to PISA results, their scores do not converge toward other countries that they are tied to in global networks with respect to the actual performance of the education systems.

\section{Conclusion}

In this study, we analyzed globalization from the vantage point of domestic secondary education systems and their performance. We measured globalization by networks of student exchange, general migration stock, and service sector trade. In so doing, we tried to separate the effects of educational performance on selection into the respective network ties from the influence of these ties on educational performance. We expected that countries connected in these networks become similar in PISA scores and rankings. The starting point of our study was the idea that globalization affects national institutions, in our case education systems, which then results in a change in the performance of secondary education as measured by PISA scores and rankings. 
Following the literature on globalization, we regarded these networks as channels of influence. The benchmarking of education systems provided by the PISA study intensified competition and increased the pressure on national policymakers. If imitation of or learning from other countries are ways of coping with this competition, the underlying social networks can provide information on more successful countries. Indeed, if researchers argue that countries increasingly influence each other due to globalization, they must specify the specific forms of social interaction between countries as conditions of influence. Our focus on these networks assumes horizontal interdependencies, that is, we regard countries as equal 'peers' that deliberately establish contact among each other. Of course, the outcome of this network formation process is not an equal distribution of network ties but a highly structured topology. In many cases, just a few countries are at the core of the respective network and have an extraordinarily high number of incoming and outgoing ties (Windzio et al. 2019).

According to our empirical results, however, there is neither a considerable selection of network ties according to PISA scores or rankings, nor any indication of social influence. Thus, we conclude that the performance of domestic systems of secondary education does not depend on their embeddedness in global networks. This does not mean, however, that education systems themselves were not responsive to the influence of globalization. Some countries responded quite sensitively. They quickly implemented reforms when they found themselves with rankings that were far below their expectations (Martens et al. 2014). Yet, simply reforming educational institutions and doing so in order to increase their performance are two very different matters. In the end, the results of our study are rather pessimistic about the effects of globalization on the actual performance of secondary education systems. Perhaps, in some cases, countries' reforms are implemented to gain legitimacy so that the implementation is more of a performative act (Steiner-Khamsi 2012) and 'myth and ceremony' (Meyer and Rowan 1977). In so doing, countries gain legitimacy as well as better access to resources from the environment. As we know from sociological neo-institutionalism, this does not mean that the performance of the organization's technical core, which generates levels of educational performance in our case, is improved as well. 
Contrariwise, organizations often establish buffer zones that regulate transactions with the (institutionalized) environments but at the same time protect and conserve their technical core (Thompson 2004).

In this chapter, a potential causal effect between PISA rankings and migration or student mobility patterns cannot be established. It is possible that the real-time lag between the reputation change of a country and its effect on individual decisions regarding migration destinations is not covered in our data.

Additionally, globalization in the field of secondary education is perhaps not driven by horizontal interdependencies but by top-down influence exerted by IOs, as shown in previous research. If so, then the global diffusion of the 'best ways to educate' will not be driven by bottom-up evolutionary processes of tie creation or by tie dissolution in networks between countries but by the focused and ongoing activities of IOs.

To conclude our answers to the questions explored in this chapter, we can confidently say that migration, student exchange, and service sector trade are highly interrelated; however, these interrelations do not depend on nor correlate with PISA rankings or scores. This finding supports both Wallerstein's World Systems Theory-since Wallerstein emphasizes the interdependencies of countries, which proved to be stable in this analysis - and Meyer and colleagues' World Society Theory-which emphasizes the influence of IOs over horizontal influences. Meyer and colleagues not only demonstrate the influence of world society but also emphasize the additional effect of vertical interdependences such as IO pressure as a reason for structural isomorphism. Wallerstein, on the other hand, emphasizes the relative stability of international interdependencies like trade and migration, an effect that we could observe here as well.

While vertical interdependencies might influence national politics, we cannot observe horizontal interdependencies influencing the outcomes, which in our case is the performance of secondary education. Vertical interdependencies, such as pressure and influences from IOs, here in the form of PISA rankings, may affect policymakers but do not seem to affect the education system's performance to the same extent. Vice versa, we cannot confirm whether education systems' outcomes converge toward 
an isomorphic 'PISA-friendly' format, due to the influences of horizontal interdependencies such as increasing migration patterns or student mobility.

\section{References}

Addey, Camilla, Sam Sellar, Gita Steiner-Khamsi, Bob Lingard, and Antoni Verger. 2017. The Rise of International Large-Scale Assessments and Rationales for Participation. Compare: A Journal of Comparative and International Education 47 (3): 434-452. https://doi.org/10.1080/0305792 5.2017.1301399.

Alderson, Arthur S., and Jason Beckfield. 2004. Power and Position in the World City System. American Journal of Sociology 109 (4): 811-851. https:// doi.org/10.1086/378930.

Barnett, George A., and Reggie Yingli Wu. 1995. The International Student Exchange Network: 1970 \& 1989. Higher Education 30 (4): 353-368. https://doi.org/10.1007/BF01383539.

Barnett, George A., Moosung Lee, Ke Jiang, and Han Woo Park. 2016. The Flow of International Students from a Macro Perspective: A Network Analysis. Compare: A Journal of Comparative and International Education 46 (4): 533-559. https://doi.org/10.1080/03057925.2015.1015965.

Beghin, John, and Byungyul Park. 2019. The Exports of Higher Education Services from OECD Countries to Asian Countries, a Gravity Approach. SSRN Electronic Journal. https://doi.org/10.2139/ssrn.3371123.

Bieber, Tonia, and Kerstin Martens. 2011. The OECD PISA Study as a Soft Power in Education? Lessons from Switzerland and the US. European Journal of Education 46 (1): 101-116.

Boyle, Paul J., Keith Halfacree, and Vaughan Robinson. 1998. Exploring Contemporary Migration. Harlow and Essex: Longman.

Castles, Stephen, Hein de Haas, and Mark J. Miller. 2014. The Age of Migration: International Population Movements in the Modern World. 5th ed. Basingstoke: Palgrave Macmillan.

Dobbin, Frank, Beth Simmons, and Geoffrey Garrett. 2007. The Global Diffusion of Public Policies: Social Construction, Coercion, Competition, or Learning? Annual Review of Sociology 33 (1): 449-472. https://doi. org/10.1146/annurev.soc.33.090106.142507.

Gersen, Jeanny S. 2017. The Uncomfortable Truth about Affirmative Action and Asian Americans. The New Yorker, August 10. 
Glick Schiller, Nina, Linda Basch, and Cristina Blanc-Szanton. 1992. Transnationalism: A New Analytic Framework for Understanding Migration. Annals of the New York Academy of Sciences 645: 1-24. https://doi. org/10.1111/j.1749-6632.1992.tb33484.x.

Greene, William H., and David A. Hensher. 2010. Modeling Ordered Choices: A Primer. Cambridge: Cambridge University Press.

Griffiths, Tom G., and Robert F. Arnove. 2015. World Culture in the Capitalist World-System in Transition. Globalisation, Societies and Education 13 (1): 88-108. https://doi.org/10.1080/14767724.2014.967488.

Harris, Jenine K. 2014. An Introduction to Exponential Random Graph Modeling. London: Sage.

Head, Keith, and Thierry Mayer. 2014. Gravity Equations: Workhorse, Toolkit, and Cookbook. In Handbook of International Economics, ed. Gita Gopinath, Elhanan Helpman, Kenneth Rogoff, vol. 4: 131-195. Amsterdam: Elsevier North-Holland

Jennissen, Roel. 2007. Causality Chains in the International Migration Systems Approach. Population Research and Policy Review 26 (4): 411-436. https:// doi.org/10.1007/s11113-007-9039-4.

Kijima, Rie. 2010. Why Participate? Cross-National Assessments and Foreign Aid to Education. International Perspectives on Education and Society vol. 13. https://doi.org/10.1108/S1479-3679(2010)0000013005.

Kuhlmann, Johanna, Delia González de Reufels, Klaus Schlichte, and Frank Nullmeier. 2020. How Social Policy Travels: A Refined Model of Diffusion. Global Social Policy 20 (1): 80-96. https://doi.org/10.1177/ 1468018119888443.

Lacroix, Thomas, Peggy Levitt, and Ilka Vari-Lavoisier. 2016. Social Remittances and the Changing Transnational Political Landscape. Comparative Migration Studies 4 (16). https://doi.org/10.1186/s40878-016-0032-0.

Maoz, Zeev. 2011. Networks of Nations: The Evolution, Structure, and Impact of International Networks, 1816-2001. Cambridge and New York: Cambridge University Press.

Martens, Kerstin, Philipp Knodel, and Michael Windzio, eds. 2014. Transformations of the State: A New Constellation of Statehood in Education? Basingstoke: Palgrave Macmillan.

Mayer, Thierry, and Soledad Zignago. 2011. Notes on CEPII's Distances Measures: The GeoDist Database. Vol. 25 CEPII Working Paper, N²011-25, December 2011, CEPII.

Melitz, Jacques, and Farid Toubal. 2012. Native Language, Spoken Language, Translation and Trade. Vol. 17. CEPII Working Paper 2012-17, July 2012, CEPII. 
Meyer, John W., and Brian Rowan. 1977. Institutionalized Organizations: Formal Structure as Myth and Ceremony. American Journal of Sociology 83: 340-363. https://doi.org/10.1086/226550.

Meyer, John W., Francisco O. Ramirez, and Yasemin N. Soysal. 1992. World Expansion of Mass Education, 1870-1980. Sociology of Education 65 (2): 128-140. https://doi.org/10.2307/2112679.

Meyer, John W., John Boli, George M. Thomas, and Francisco O. Ramirez. 1997. World Society and the Nation-State. American Journal of Sociology 103 (1): 144-181. https://doi.org/10.1086/231174.

Niemann, Dennis. 2014. After the Big Bang-German Education Policy in the Wake of the PISA Study and the Bologna Process. In Transformations of the State: A New Constellation of Statehood in Education? ed. Kerstin Martens, Philipp Knodel, and Michael Windzio, 91-114. Basingstoke: Palgrave Macmillan.

Obinger, Herbert, Carina Schmitt, and Peter Starke. 2013. Policy Diffusion and Policy Transfer in Comparative Welfare State Research. Social Policy \& Administration 47 (1): 111-129. https://doi.org/10.1111/spol.12003.

Peterson, Ronald E., Vassily Aksyonov, and Michael Henry Heim. 1984. The Island of Crimea. The Slavic and East European Journal 28 (3): 410-411. https://doi.org/10.2307/307846.

Robertson, Susan L., and Roger Dale. 2015. Towards a 'Critical Cultural Political Economy' Account of the Globalising of Education. Globalisation, Societies and Education 13 (1): 149-170. https://doi.org/10.1080/1476772 4.2014.967502.

Shields, Robin. 2013. Globalization and International Student Mobility: A Network Analysis. Comparative Education Review 57 (4): 609-636. https:// doi.org/10.1086/671752.

Snijders, Thomas A., Gerhard de van Bunt, and Christian E.G. Steglich. 2010. Introduction to Stochastic Actor-Based Models for Network Dynamics. Social Networks 32: 44-60. https://doi.org/10.1016/j.socnet.2009.02.004.

Steglich, Christian, Tom A. B. Snijders, and Michael Pearson. 2010. "Dynamic Networks and Behavior: Separating Selection from Influence." Sociological Methodology 40 (1): 329-393. https://doi.org/10.1111/ j.1467-9531.2010.01225.x.

Steiner-Khamsi, Gita. 2012. Transferring Education, Displacing Reforms. In Discourse Formation in Comparative Education, ed. Jürgen Schriewer, 4th ed., 155-187. Frankfurt: Peter Lang.

. 2014. Cross-National Policy Borrowing: Understanding Reception and Translation. Asia Pacific Journal of Education 43 (2): 153-167. https:// doi.org/10.1080/02188791.2013.875649. 
Teltemann, Janna, and Michael Windzio. 2019. The Impact of Marketisation and Spatial Proximity on Reading Performance: International Results from PISA 2012. Compare 49 (5): 777-794. https://doi.org/10.1080/0305792 5.2018.1458597.

Thompson, James D. 2004. Organizations in Action: Social Science Bases of Administrative Theory. New Brunswick, NJ: Transaction publishers.

UNCTADstat Trade in Goods and Services. 2020. Goods and Services (BPM6): Trade Openness Indicators, Annual. Accessed 11 November 2020. https:// unctadstat.unctad.org/wds/ReportFolders/reportFolders.aspx.

UNESCO Institute for Statistics. 2020. Inbound Internationally Mobile Students by Country of Origin. Accessed 11 November 2020. http://data.uis.unesco. org/index.aspx?queryid $=181$.

United Nations Department of Economic and Social Affairs. Population Division. 2019. International Migrant Stock 2019. Accessed 11 November 2020. https:/www.un.org/en/development/desa/population/migration/ data/estimates2/estimates19.asp.

Vögtle, Eva Maria, and Michael Windzio. 2016. Networks of International Student Mobility: Enlargement and Consolidation of the European Transnational Education Space? Higher Education 72 (6): 723-741. https:// doi.org/10.1007/s10734-015-9972-9.

Vögtle, Eva M., and Michael Windzio. 2020. Looking for Freedom? Networks of International Student Mobility and Countries' Levels of Democracy. The Geographical Journal 186 (1): 103-115. https://doi.org/10.1111/geoj.12329. Waldow, Florian, Keita Takayama, and Youl Kwan Sung. 2014. Rethinking the Pattern of External Policy Referencing: Media Discourses over the 'Asian Tigers' PISA Success in Australia, Germany and South Korea. Comparative Education 50 (3): 302-321. https://doi.org/10.1080/03050068.2013.860704.

Wallerstein, Immanuel. 1995. Die Sozialwissenschaft 'kaputtdenken'. Die Grenzen der Paradigmen des 19. Jahrhunderts. Weinheim: Beltz.

Walsh, Keith. 2011. Trade in Services: Does Gravity Hold? A Gravity Model Approach to Estimating Barriers to Services Trade. SSRN Electronic Journal 183. https://doi.org/10.2139/ssrn.945335.

Windzio, Michael. 2018. The Network of Global Migration 1990-2013: Using ERGMs to Test Theories of Migration between Countries. Social Networks 53: 20-29. https://doi.org/10.1016/j.socnet.2017.08.006.

Windzio, Michael, Kerstin Martens, and Alexander K. Nagel. 2010. Education Policy, Globalization, and the Changing Nation State-Accelerating and Retarding Conditions. In Transformation of Education Policy, ed. Kerstin 
Martens, Alexander-Kenneth Nagel, Michael Windzio, and Ansgar Weymann, 261-276. Basingstoke: Palgrave Macmillan.

Windzio, Michael, Céline Teney, and Sven Lenkewitz. 2019. A Network Analysis of Intra-EU Migration Flows: How Regulatory Policies, Economic Inequalities and the Network-Topology Shape the Intra-EU Migration Space. Journal of Ethnic and Migration Studies 45: 1-19. https://doi.org/10.108 0/1369183X.2019.1643229.

World Bank. 2019. World Development Indicators Database. Accessed 11 November 2020. https://databank.worldbank.org/source/world-developmentindicators.

- 2020. World Development Indicators. Total Population. The World Bank Group. Accessed 11 November 2020. https://data.worldbank.org/indicator/ SP.POP.TOTL.

Zhao, Yong. 2020. Two Decades of Havoc: A Synthesis of Criticism against PISA. Journal of Educational Change 21 (2): 245-266. https://doi. org/10.1007/s10833-019-09367-x.

Open Access This chapter is licensed under the terms of the Creative Commons Attribution 4.0 International License (http://creativecommons.org/licenses/ by/4.0/), which permits use, sharing, adaptation, distribution and reproduction in any medium or format, as long as you give appropriate credit to the original author(s) and the source, provide a link to the Creative Commons licence and indicate if changes were made.

The images or other third party material in this chapter are included in the chapter's Creative Commons licence, unless indicated otherwise in a credit line to the material. If material is not included in the chapter's Creative Commons licence and your intended use is not permitted by statutory regulation or exceeds the permitted use, you will need to obtain permission directly from the copyright holder.

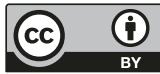

